\title{
DIRETRIZES PARA O PROJETO DE EDIFÍCIOS VOLTADOS PARA O APOIO AO ENSINO SUPERIOR REALIZADO ATRAVÉS DO EAD NO BRASIL
}

\section{GUIDELINES FOR THE PROJECT OF BUILDINGS FOR THE SUPPORT FOR HIGHER EDUCATION ACHIEVED THROUGH DISTANCE EDUCATION IN BRAZIL}

\author{
Roberta Betania Ferreira Squaiella ${ }^{1}$, Roberto Righi $^{2}$
}

\section{RESUMO}

Este artigo posiciona-se frente à intensa e crescente expansão recente do ensino superior à distância no Brasil devido a condicionantes como: o surgimento de novas concepções pedagógicas; a clara emergência do aluno nativo digital; o rápido desenvolvimento das tecnologias de informação e comunicação; a eclosão de novas legislações que perseguem o estímulo ao aumento quantitativo e qualitativo da estrutura educacional. Vive-se a era do conhecimento com a afirmação do teletrabalho e a banalização do lugar e a necessidade das relações assíncronas, impossíveis de serem respondidas pelo ensino unicamente presencial. Tudo isto possui fortes consequências para o projeto arquitetônico escolar, que precisa ser aperfeiçoado, tanto na sede, como nos polos de apoio presencial, envolvendo a infraestrutura física e os apoios essenciais para a operacionalidade dos cursos. A metodologia empregada é pesquisa bibliográfica, enfocando a caracterização do processo em âmbito nacional e internacional. Os resultados alcançados constituem-se em diretrizes a serem aplicadas em projetos de espaços físicos de apoio ao ensino a distância e híbridos.

PALAVRAS-CHAVE: Projeto de edifícios. Ensino a distância. Ensino superior. Arquitetura escolar.

\section{ABSTRACT:}

This article stands in the face of the intense and growing recent expansion of distance higher education in Brazil due to such factors as: the emergence of new pedagogical conceptions; the clear emergence of the native digital student; the rapid development of information and communication technologies; the emergence of new legislation that seeks to stimulate the quantitative and qualitative increase of the educational structure. The era of knowledge is lived with the assertion of telework and the trivialization of the place and the need for asynchronous relationships, impossible to be answered by the classroom-only teaching. All of this has strong consequences for the school's architectural project, which needs to be improved, both at headquarters and at the poles of face-to-face support, involving the physical infrastructure and the essential supports for the operation of the courses. The methodology used is bibliographic research, focusing on the characterization of the process in national and international scope. The results obtained are guidelines to be applied in projects of physical spaces in support of distance learning and hybrids.

KEYWORDS: Building design. Distance education. Higher education. School architecture.

1 Doutora em Arquitetura e Urbanismo pela FAU-Universidade Presbiteriana Mackenzie. Professora da ETEC Guaracy Silveira. Correio eletrônico: robssquaiella@gmail.com

2 Doutor em Arquitetura e Urbanismo pela FAU-Universidade de São Paulo. Professor Titular da FAU-Universidade Presbiteriana Mackenzie. Correio eletrônico: roberto.righi@mackenzie.com 


\section{INTRODUÇÃO}

O problema a ser enfrentado é o espaço arquitetônico necessário para o novo paradigma de ensino e aprendizagem, representado pelo ensino a distância (EAD) e suas formas híbridas. Os espaços novos necessários para o EAD são distintos daqueles necessários para o ensino presencial, devendo sua adequação resultar em reformas ou novas construções.

$\mathrm{Na}$ era da cibercultura há novas relações e interações comunicacionais que resultam em mudanças educacionais, tais como a maior integração da utilização das tecnologias de informação e comunicações (TICs) no ambiente de ensino e aprendizado, que altera as concepções pedagógicas e as configurações do espaço físico. No Brasil, nos últimos 10 anos houve forte expansão do ensino a distância acompanhando o processo internacional, condicionado localmente, exigindo esta reflexão e resposta.

Considerando a educação em nível superior, a docência universitária está passando por um processo de transformação, pois de um lado os estudantes, desinteressados, se tornam profissionais despreparados para a profissão que devem exercer, e os professores estão presos a modelos pedagógicos ultrapassados. Por outro lado, a sociedade toma consciência de que a formação de nível superior é cada vez mais requerida para o mercado de trabalho e o desenvolvimento do país. É preciso pensar o ensino superior em bases totalmente novas, nas quais o centro seja o aluno, as suas necessidades efetivas e o seu engajamento social, enquanto o professor assume o papel de articulador e estimulador da sua aprendizagem, além de mediar o saber existente e a realidade social em que ele vive.

Diante da enorme expansão recente do ensino a distância no Brasil julga-se necessário identificar as necessidades das instituições de ensino superior a distância para que estas possam promover um ensino com qualidade, dentro de uma infraestrutura física eficiente e com os suportes tecnológicos adequados para o aluno contemporâneo. Surgem assim algumas indagações: Como devem ser as instituições de EAD para atender o aluno do século XXI? O que difere uma instituição de ensino presencial de outra que emprega o ensino a distância, considerando a infraestrutura física e o suporte tecnológico necessário? Quais são as diretrizes estabelecidas pelas legislações vigentes para a instituição de ensino a distância? Tais legislações atendem as reais necessidades do ensino a distância ou é apenas uma transposição do ensino presencial?

Os princípios da pesquisa científica que serão adotados no trabalho são: precisão, exaustão, clareza e exterioridade; visando apresentar documento adequado à pretensão, acrescidos da contextualização da informação, referências corretas, austeridade e espírito científico. A modalidade da pesquisa é bibliográfica, devido à dificuldade de generalização do tema, frente a sua atualidade e a diversidade de casos e iniciativas, resultando na falta de modelos consolidados e experimentados. Esta pesquisa envolve definir o estado da questão, buscando coerência e atualidade dos temas de: desenvolvimento do EAD e TIC no ensino brasileiro, a educação e o ciberespaço, a legislação pertinente ao assunto, as transformações na arquitetura do espaço escolar, organização do espaço para o aprendizado colaborativo, e finalmente a infraestrutura física, tecnológica e de suportes para as instituições de EAD.

\section{DESENVOLVIMENTO RECENTE DO ENSINO A DISTÂNCIA}

Nos últimos quarenta anos houve um crescimento acentuado do ensino a distância, principalmente nos Estados Unidos e na Europa. Infelizmente, no Brasil a expansão desta modalidade foi tardia e para o ensino superior, só ocorreu principalmente nos últimos treze anos, quando o decreto 5.622 de 2005 equiparou o ensino a distância ao ensino presencial e houve abertura da educação superior para a iniciativa privada.

Considerando os estudos de Ropoli et al. (2002) sobre o contexto histórico do EAD, adota-se a divisão de três períodos com marcos referenciais a utilização da tecnologia no processo de mediação pedagógica. A primeira fase é vista como a geração textual (1890 a 1960), apoiada no estudo por correspondência. Geralmente estava orientada em um guia de estudos com exercícios escritos e tarefas realizadas e enviadas pelos correios. Os países que mais a impulsionaram foram: Estados Unidos, União Soviética, Alemanha, Grécia, Inglaterra, e depois a Austrália e os países da América Latina.

A segunda geração, conhecida como analógica (1960 a 1980) surgiu das Universidades Abertas, sendo 
a primeira no Reino Unido em 1969 (Open University). A universidade aberta era um sistema educativo voltado a democratização do saber. A contribuição dessa geração para o EAD é que a ênfase não era apenas o material impresso, mas o trabalho sistêmico, pois combinava: encontros presenciais, sessões de tutoria, transmissão através de rádio e de televisão, bem como suporte de áudio e de vídeo. A Open University difundiu-se para outros países, em seu modelo institucional e pedagógico adaptado para: Alemanha, Paquistão, Israel, Canadá, Austrália, Costa Rica, Venezuela, Japão, Índia, Irlanda, França e Espanha.

A terceira geração de cursos de ensino a distância surgiu a partir dos anos 1980, caracterizada pela inserção das novas tecnologias de informação e comunicação baseadas em redes de computadores, com comunicação síncrona ou assíncrona através de: chats, fóruns, listas de discussão e outros. Os trabalhos desenvolvidos nessa geração, de certa forma, permitem a universalização do aprendizado através dos avanços tecnológicos. O baixo custo e o alto grau de interatividade dos computadores dá novo ritmo à educação, agora global, em que a inovação e a descoberta fazem parte do processo de aprendizagem.

Atualmente, muitas instituições oferecem cursos de EAD, atendendo um mercado crescente. Nas mídias informam sobre a quantidade de cursos e de espaços de apoio destinados aos alunos - os polos de apoio presencial -, que se espalham pelas mais diversas regiões do país, apontando para a facilidade de acesso ao ensino. De acordo com os dados do Censo da Educação Superior 2016 (INEP/MEC, 2017), em 2006 havia cerca de 207.206 alunos em cursos a distância ou $4,2 \%$ do total dos matriculados, e que em 2016 passaram para cerca de 1 milhão e 494 mil alunos ou 18,6\% do total dos matriculados, num crescimento excepcional de $721 \%$ em dez anos ou de aproximadamente $24 \%$ ao ano, conforme demonstrado no Gráfico1. Destaca-se que o número de matrículas em cursos de graduação a distância cresceu $7,2 \%$ entre os anos de 2015 e 2016, enquanto nos cursos presenciais este crescimento foi negativo de $1,2 \%$.

Gráfico 1: Evolução das matrículas de educação superior de graduação, por modalidade de ensino - Brasil, 2006 -2016 Evolution of undergraduate higher education enrollments by type of education -

Brazil (2006 - 2016)

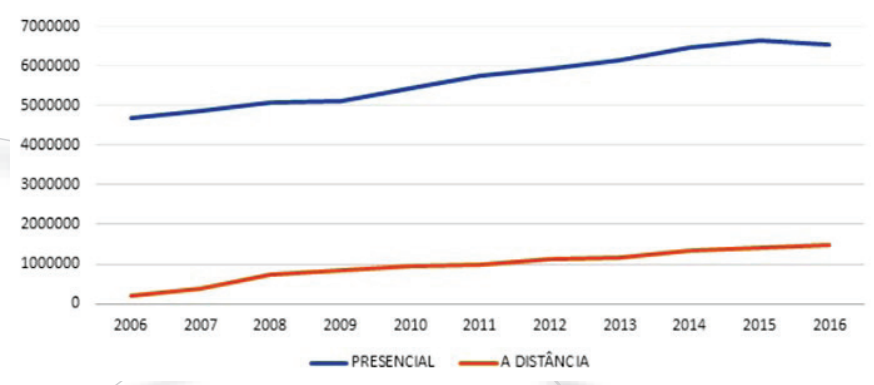

Fonte: SQUAIELLA, 2018, com base no Censo da Educação Superior 2016 (INEP/MEC, 2017).

Vários fatores explicam este crescimento vertiginoso e exponencial. Os mais relevantes são: o menor custo para o aluno, as limitações de mobilidade urbana e o maior uso dos recursos multimídias com o desenvolvimento e inserção das tecnologias da informação e da comunicação (TIC) no processo de ensino-aprendizagem (DECCACCHE, 2015). Outras mudanças podem ser atribuídas às alterações intrínsecas ocorridas no ensino superior brasileiro e às transformações da estrutura econômica, marcada pela nova economia que gera a necessidade crescente da educação continuada e a melhoria da credibilidade do ensino a distância (SQUAIELLA, RIGHI, 2015).

\section{ENSINO, EDUCAÇÃO, APRENDIZAGEM E TRABALHO}

É importante destacar que as mudanças econômicas e sociais ocorridas na sociedade contemporânea se refletem em novas demandas ao ensino, pois a formação em nível superior passa a ser condição cada vez mais requerida para o ingresso no mercado de trabalho. Além disso, a necessidade de formação continuada para atualização e adequação a vida profissional, aponta para os novos caminhos onde o ensino a distância se apresenta como alternativa mais viável, pois permite que a aprendizagem ocorra de forma livre das limitações de tempo e espaço, em qualquer lugar e horário (SQUAIELLA, 2016).

Hoje há três modalidades de ensino por meio do uso das tecnologias: híbrido, semipresencial e a distância. O híbrido (blended learning) combina o aprendizado on-line e off-line, onde o aluno estuda virtualmente, no local e no momento que quiser, e também nos encontros presenciais, podendo realizar atividades individuais e/ou interações interpessoais com os colegas e o tutor/ 
professor. $\mathrm{O}$ ensino on-line se desenvolve por meio da aprendizagem em plataformas virtuais. De acordo com a legislação vigente, um curso presencial pode ofertar até $20 \%$ da sua carga horária total na modalidade a distância, com a realização presencial das avaliações. $O$ ensino semipresencial utiliza as novas tecnologias para o ensino on-line, porém mantém carga horária presencial regular, que pode ocorrer, por exemplo, em encontros semanais ou mensais. No ensino a distância os encontros presenciais são reduzidos, concentrando-se geralmente início e fim do curso e nas atividades avaliativas.

Hoje a evasão dos alunos dos cursos de ensino a distância preocupa os professores, os tutores e os demais envolvidos. O learning management system (LMS) e os ambientes virtuais de aprendizagem (AVA) são os principais meios de suporte à educação on-line. Ambos devem ser integrados. O primeiro, o LMS, dá funcionalidade para o gerenciamento dos cursos. O segundo, o AVA, torna possível o contato síncrono e assíncrono das funções necessárias para a evolução do conhecimento e da inteligência coletiva. A Web 2.0 opera na integração das ferramentas de comunicação num todo dinâmico e mutável, onde os alunos atuam de forma colaborativa e descentralizada, base da cultura contemporânea. A caixa de ferramentas da Web 2.0 é excepcional e envolve: softwares de redes sociais (blogs, Facebook, Twiter); bem como inúmeros aplicativos para: edição colaborativa (blogs, wikis, podcasts, google docs), comunicação on line (Skype, volp, google talk), vídeos (YouTube, google vídeos) e bookmark social (delicious). Estudos recentes ainda indicam também o potencial do uso de adequações às inteligências múltiplas dos alunos e a utilização importante de jogos eletrônicos como estratégias de melhora do sucesso.

A educação segundo Gadotti (1984) constitui-se de um complexo processo, de perfil contínuo e com diversas finalidades, começando pelo indivíduo que adquire capacidade de transformar a si mesmo, e de forma mais ampla como agente de mudança da natureza e da sociedade, em prol da liberdade e realização da humanidade. Esta visão humanista e universal possui enorme relevância para a construção na época contemporânea de uma nova concepção de educação. A tecnologia avança rapidamente e para Moran (2000) o desenvolvimento de uma educação atual, desafio presente, não é uma questão meramente técnica. Ensinar e aprender, binômio da educação, devem ser adequados a transi- ção do modelo de gestão industrial para o da informação e do conhecimento. Isso é fundamental para realizar a difícil transposição, que deve ser construída num diálogo entre os valores individuais e universais num meio contemporâneo imerso nas tecnologias de informação e comunicação.

As sete fases da aprendizagem, segundo Furtado dos Santos (2012), envolvem várias dimensões necessárias para a interpretação da realidade, a saber: o sentir, o perceber, o compreender, o definir, o argumentar, o discutir e o transformar. O sentir dá o significado contextual e emocional global, que constrói o sentido do objeto no seu mundo. O perceber traz as características específicas do objeto, criando um conceito. O compreender envolve a construção de um conceito, resultado das características e fatos sobre algo. O definir esclarece um conceito, definindo-o. O argumentar relaciona os conceitos num discurso falado, escrito, verbal ou não verbal. O discutir resulta em um encadeamento de raciocínio por meio da argumentação. Finalmente, o transformar constitui-se na verdadeira reconstrução do conhecimento, cujo último fim é a intervenção na realidade. $O$ processo de aprendizagem atual deve ser diferente do tradicional. Não há mais sentido aquela aula, onde o aluno é apenas um expectador. No passado o "mundo estava pronto" e o conhecimento era cristalizado, refletindo aquele ambiente, e a escola só o transmitia. Hoje o mundo está em construção, o conhecimento é provisório, e a aprendizagem deve ser significativa, com o professor a promovendo, através do desafio contínuo aos alunos.

Pastore (2014) considera que as tecnologias evoluem e que exigem novas habilidades para o trabalho e a vida. Ele extrapola afirmando que dentro de dez anos, a maior parte dos seres humanos trabalhará com técnicas ainda não inventadas hoje, e que só acompanharão a evolução tecnológica os que tiverem bom senso, lógica de raciocínio, capacidade de transformar informações em conhecimentos e que trabalhem em grupo.

Da globalização e das tecnologias de informação e comunicação surgem a cibercultura e a fluidez, que geram mudanças no trabalho e na vida. A cibercultura constitui-se de um conjunto de técnicas materiais e intelectuais, que se desenvolvem com o ciberespaço. $\mathrm{O}$ impacto disto na educação envolve a mudança do conhecimento e a obsolescência da formação. O trabalho atual exige conhecimentos novos; novas tecnologias alteram funções cognitivas; o aprendizado deixa de ser rígido e 
previsível. Estas mudanças levam a duas grandes reformas no ensino: incorporação de ferramentas tecnológicas e o reconhecimento das experiências adquiridas, como os links entre bancos de dados, hipertextos e redes que se multiplicam (LÉVY, 1999). A fluidez constitui uma metáfora entre os estados sólido e líquido, frente aos fenômenos urbanos e sociais, gerando mobilidade, efemeridade e flexibilidade, marcados pela não corporificação e não territorialização (BAUMAN, 2000). Na educação cria a ruptura da escola tradicional, estática e rígida. Para a necessária mudança novas configurações espaciais são necessárias.

Conforme Harvey (1989), o capitalismo é tecnologicamente dinâmico, não por causa da capacidade do empreendedor inovador, mas devido às leis da competição e das condições de luta de classe. Havendo flexibilidade, os trabalhadores conseguirão se ajustar, tirando proveito inclusive das novas formas de aprendizagem, como a grande quantidade de cursos a distância viabilizados pela Internet.

O ensino a distância pode representar poderosa resposta para superar as deficiências atuais no ensino. Mozart Neves Ramos (2012), no Conselho Nacional de Educação afirmou que: "O Brasil ainda tem uma escola do século XIX, professores do século XX e alunos do século XXI". Sua frase denuncia a gravidade da situação do ensino no país.

\section{OS GÊNEROS TEXTUAIS NAS FERRAMENTAS VIRTUAIS}

É importante afirmar que a linguagem do texto deve ser adequada à situação, ao perfil do interlocutor e ao objetivo da comunicação, essencial para a sua eficiência, apesar de ser possível admitir certa relatividade. Há diferentes níveis de linguagem e de formas de expressão, sintetizadas pelos níveis culto, familiar e popular. O registro formal é o culto, mais utilizado na forma escrita, que possui vocabulário rico e respeito pelas normas gramaticais. Os registros comum ou familiar e o informal ou popular são incultos e cotidianos, apesar de ser utilizado pelos meios de comunicação de massa. Também, na Internet surgiu a linguagem do Internetês que permite uma comunicação informal e rápida, produto da mescla híbrida entre a língua oral e escrita, cria reduções de caracteres e uso de emotions.

Esta linguagem e a informal são inadequadas para o uso no processo de aprendizagem, que deve estimular o emprego da linguagem erudita correta. $\mathrm{O}$ texto é resultado de uma intertextualidade, formando uma rede de ligações internas e externas com outros textos. A produção textual se dá segundo gêneros textuais que apresentam características estáveis de tema, estrutura textual e estilo com as finalidades de narrar, relatar, argumentar, expor e descrever ações; conforme a natureza linguística de sua composição. As capacidades ou competências da criação textual são três: formativa, transformativa e qualificativa; que permitem a condução de textos bem construídos.

Com o surgimento das tecnologias de informação e comunicação, como o telefone, o rádio e outras, e mais recentemente da Internet, houve uma verdadeira explosão na mudança dos gêneros textuais. Assim, ao contrário do que ocorria no passado, os gêneros textuais contemporâneos são de difícil definição formal, formando verdadeiras transmutações, cada vez mais integrados com signos verbais, sons, imagens e mesmo formas em movimentos; usados nos emails, bate-papo, aulas virtuais e outros. Dessa forma, com o avanço das TICs cresce o acervo de ambientes e suportes textuais digitais, especialmente na forma hipertextual e outras, que vão até além da linearidade e autoria. As redes de Internet trazem todos para todos, com interações complexas, totais e globalizadas, feitas segundo novas acessibilidades, linguagens e discursos. A construção textual gera novos códigos e terminologias vocabulares, exigindo em compensação: clareza, concisão e brevidade. Os novos gêneros textuais virtuais acompanham as mudanças e geram formas de comunicação emergentes que devem respeitar no caso do EAD, os atributos presentes na boa textualidade já descritos.

O conjunto das principais ferramentas abrange: o email, o chat, o fórum, o MSN, a sala de conferências e vídeos-aula, blogs, flogs, moblogs e redes sociais de relacionamento. $\mathrm{O}$ primeiro é o email, que substitui as antigas cartas, constituindo-se no principal meio de comunicação na Internet. As suas grandes vantagens são a rapidez, escala, liberdade, flexibilidade e baixo custo. O chat possui a sincronia, que apesar de interessante gera superficialidade e imprecisão, devido à premência da resposta. No fórum, de natureza assíncrona, há fértil campo para a comunicação dialógica, com reflexão e precisão de idéias e linguagem. O MSN permite que a informação vá síncrona, com grande flexibilidade. As 
salas de conferências e vídeos-aula ampliam as relações entre aluno e professor através da interatividade, permitindo a conversação, aumentando a produtividade no EAD. Os Blogs, Flogs e Moblogs permitem publicar na Internet qualquer informação, só fotos ou enviar conteúdos de celulares, respectivamente (DORSA, 2016). Constituem formas muito práticas de divulgar e interagir com outros internautas.

É importante afirmar que o texto não é apenas uma sequência de frases, mas sim uma ocorrência comunicativa, com ações linguísticas, cognitivas e sociais, num tecido com estrutura e organização. A coerência envolve o sentido do texto. A coesão trata da ligação dos componentes do texto numa sequência. Aceitabilidade considera a atitude favorável ou não do leitor em relação ao texto. A informatividade abrange a capacidade de tornar o texto mais interessante ao leitor, com incorporação de novidades do produtor. A situacionalidade aponta quanto é compreensível o texto em determinado contexto. A intertextualidade envolve a construção do texto em função a outros textos já conhecidos. A intencionalidade constitui o objetivo do texto em informar, impressionar, convencer e outros itens. Esse conjunto de atributos define o bom texto.

\section{REGULAMENTAÇÃO DO ENSINO A DISTÂNCIA NO BRASIL}

O ensino superior a distância no Brasil é atualmente pela Internet, e não elimina a relação do aluno com a escola física, que pode ser na unidade central ou nos polos de apoio presencial. Esta infraestrutura educacional é requisito básico para os Referenciais de Qualidade do MEC. É necessário que o arquiteto a conceba segundo as necessidades emergentes das redes institucionais de ensino, para a sua sede e os polos de apoio presencial. Isto deve ocorrer em conformidade com a legislação pertinente à questão no país, que exige períodos presenciais para avaliação e apoio discente.

Considera-se essencial que o EAD possua regulamentação. Tanto é importante isto, que só a partir de sua existência que esta cresceu e adquiriu maturidade. Quanto aos seus aspectos históricos e ao quadro normativo, a educação à distância foi introduzida no sistema educacional brasileiro pela Lei de Diretrizes e Bases da Educação - LDB (Lei n 9.394, de 20/12/1996), nos seus artigos 80 e 87 (BRASIL, 1996), onde esta modalidade de ensino apresenta-se como atendimento às soluções complementares e emergenciais para suprir a deficiência na formação de professores, de jovens e de adultos. De acordo com o Decreto n. ${ }^{\circ} 2.494$, de 10 de fevereiro de 1998, o conceito de Educação a Distância é definido, como uma forma de ensino que possibilita a autoaprendizagem, com a mediação de recursos didáticos (BRASIL, 1998). Para a valorização do ensino a distância foi essencial a sua regulamentação pelo Decreto 5.622, de 19/12/2005 (BRASIL, 2005), quando este foi equiparado ao ensino presencial da educação básica até o nível superior. Resultado do avanço na disseminação das novas tecnologias da informação e da comunicação, o conceito de ensino a distância foi redefinido neste documento como a modalidade educacional em que a "mediação didático-pedagógica nos processos de ensino e aprendizagem ocorre com a utilização de meios e tecnologias de informação e comunicação, com estudantes e professores desenvolvendo atividades educativas em lugares ou tempos diversos" (BRASIL, 2005, p1).

Destaca-se que, conforme o Art. 9, o credenciamento de instituições públicas ou privadas para a oferta de cursos e programas de nível superior na modalidade a distância, destina-se para aquelas que possuem comprovada excelência e relevante produção em pesquisa.

Diante da necessidade de se manter a qualidade do ensino, julga-se que a necessidade de credenciar o ensino a distância para instituições já experientes em ensino presencial, é uma medida coerente e adequada. Posteriormente, o decreto $n^{\circ} 5.773$, de 09/05/2006/(BRASIL, 2006), dispõe sobre o exercício das funções de regulação, supervisão e avaliação de instituições de educação superior e cursos superiores de graduação e sequenciais no sistema federal de ensino. Destaca-se que avaliação é realizada pelo Sistema Nacional de Avaliação da Educação Superior (SINAES) para os processos de regulação e supervisão da educação superior, visando qualidade. Na Portaria $n^{\circ} 1.047$, de 08/11/2007 (BRASIL, 2007a), do Ministério da Educação e pelo Conselho Nacional de Educação (MEC/CNE), verificam-se que as diretrizes para a elaboração dos instrumentos de avaliação para a oferta de educação superior a distância estão organizadas em três documentos básicos: 1) Avaliação para Credenciamento Institucional; 2) Avaliação para Autorização de Cursos; 3) Avaliação para Credenciamento de Polos. Atenta-se que não basta a aprovação de uma instituição para que se inicie na oferta de cursos a dis- 
tância. É necessária a autorização dos cursos, especificamente, e a abertura dos polos de apoio presencial, quando for o caso. No credenciamento do Polo de Apoio Presencial há necessidade de um projeto único, que contemple em seus indicadores uma descrição completa quanto implantação, as instalações físicas, a equipe de técnico-administrativo, coordenadores, tutores, recursos tecnológicos, laboratórios de informática e biblioteca. De forma focada, a Portaria Normativa n 2 (BRASIL, 2007 b), de 10 de janeiro de 2007, dispõe sobre os procedimentos de regulação e avaliação da educação superior na modalidade a distância. Destaca-se que para o credenciamento de EAD, é necessária a determinação da abrangência da instituição de ensino, para a localização dos edifícios destinados aos momentos presencias obrigatórios, sejam na sede na instituição, ou nos polos de apoio presencial. Tais polos de apoio, conforme descrito no decreto 5.622 (BRASIL, 2005), são as unidades operacionais para o desenvolvimento descentralizado de atividades pedagógicas e administrativas relativas aos cursos e programas ofertados a distância. Acredita-se que a ênfase no encontro presencial deveria ser diminuída, pois com os avanços das novas tecnologias estas atividades são confiáveis no processo de avaliação (SQUAIELLA, RIGHI, 2015).

Porém, diante da legislação, com a possibilidade de expansão dos cursos é necessário que a instituição solicite o credenciamento de novos polos de apoio, que possuam comprovada existência de estrutura física e recursos humanos necessários e adequados, sendo que o pedido de ampliação da abrangência de atuação de uma instituição, só poderá ocorrer após o reconhecimento do seu primeiro curso a distância. Observa-se que as instituições e cursos superiores na modalidade a distância sujeitam-se a supervisão, que poderá ocorrer a qualquer momento, conforme os termos dos Art. 45 a 57, do Decreto 5.773 (BRASIL, 2006). Isto confere o correto andamento das instituições de ensino, ou o seu descredenciamento em caso de situação irregular, não corrigida dentro do prazo previsto.

O documento Referenciais de Qualidade Para Educação Superior a Distância do MEC apresenta orientações que apesar de não ter força de lei, visa garantir a sua qualidade. Tais orientações são fundamentais para o alcance da qualidade do ensino e aprendizagem, alvo no planejamento e organização de um curso a distância. Esse documento parte de uma posição muito esclarecida, que reconhece que "Não há modelo único de educação a distância", (BRASIL, 2007c, p.7). A liberdade oferecida permite a melhor adequação, contextualização e definição dos diversos elementos educacionais, tecnológicos e de apoio institucional, num projeto adequado e que envolvem a diversidade de cursos, de agentes e realidades regionais, coerente com um país enorme, desigual e complexo. Em sua concepção de educação e currículo no processo de ensino e aprendizagem destaca-se a visão de construção do conhecimento voltada ao desenvolvimento humano, vinculada a construção da sociedade, segundo perspectiva interdisciplinar e contextualizada, num projeto pedagógico que valoriza o estudante.

O documento destaca também a necessidade de interação e interatividade entre os sistemas de comunicação e o ensino-aprendizagem no trinômio: professores, tutores e estudantes. As TICs, que constituem excepcional avanço tecnológico, são aplicáveis no EAD, e devem ser colocadas na posição correta como ferramentas para o seu sucesso, colaborando para os objetivos maiores do ensino e aprendizagem.

Os Referenciais de Qualidada trata também da fundamental relação entre o EAD e os encontros presenciais, voltada à superação do isolamento e a evasão dos alunos, que é cobrada por 12 pontos diferentes e basilares, definido e valorizando principalmente o papel estratégico dos pólos de apoio descentralizados. O material didático, componente básico do processo de ensino e aprendizagem, ganha ênfase mostrando a especificidade do EAD, principalmente na produção do guia geral e os dos materiais educacionais do curso. 0 processo de avaliação do ensino-aprendizagem é definido como contínuo, visando permanente acompanhamento dos alunos, na dimensão presencial e a distância. Também é dada forte ênfase na avaliação institucional em seus diversos componentes da organização pedagógica, do corpo docente, de tutores e do técnico-administrativo, bem como das instalações físicas; desembocando numa meta avaliação crítica do sistema.

Na sequência, há uma preocupação paradigmática, muito louvável, do emprego de equipe multidisciplinar, propícia a enfrentar o desafio do planejamento, implementação e gestão do EAD. Ela deve abranger todos os agentes pedagógicos, técnicos e administrativos do curso, num conjunto de tarefas enumeradas no documento, voltadas à construção e operação do projeto pedagógico, dos docentes, dos tutores a distância e pre- 
senciais, do corpo técnico-administrativo e o coordenador do polo de apoio presencial. Além disso, o Referencias de Qualidade preconiza que o dimensionamento, qualidade e gestão da infraestrutura de apoio são fundamentais para o bom desempenho do EAD; envolvendo o núcleo sede e os polos de apoio presencial, fundamentais para expansão, interiorização, regionalização e democratização da oferta de educação no Brasil. A gestão acadêmica administrativa também é destaque, diante da necessidade de integração institucional, fundamental diante da complexidade do EAD.

Finalmente, é destacada a necessidade da sustentabilidade financeira, importante diante do volume de investimentos iniciais exigidos pelo EAD, onde a consonância entre o projeto político-pedagógico, suprimento de insumos, infraestrutura e a oferta de vagas no tempo é decisivo ao sucesso do empreendimento (BRASIL, 2007c). Considera-se que, diante do cumprimento destas diretrizes dos Referenciais de Qualidade, deve ter ótimo desempenho e conceito de qualidade o curso em EAD, assim planejado e organizado.

Dessa maneira, a caracterização dada hoje para o que é educação a distância pela legislação brasileira, tem como principal relevância a utilização de recursos tecnológicos na intermediação do processo pedagógico, em que professores e alunos estão distantes física e temporalmente. Sathler (2015) considera a necessidade de revisão deste decreto, pois afirma que educação a distância não é modalidade, mas apenas educação semelhante à presencial, sem distinção legal.

Atualmente, o grande avanço das mídias e das Tecnologias da Informação e da Comunicação (TIC) possibilita uma enorme disseminação desta modalidade de ensino, e a aplicação de nova abordagem nas práticas pedagógicas da Educação Superior. Autores como: Bernini et al. (2009) e Perrenoud (2000), entre outros, concordam que o papel do professor se altera com o uso das TIC na educação, deixando de ser o detentor de conhecimentos e transmissor de informações, para ser o orientador de estudos e participante no processo de construção do saber.

Quanto ao processo de transformação da estrutura de ensino, cabe a instituição de ensino promover a infraestrutura tecnológica necessária, com a adequação das salas de aulas e equipamentos que atendam a esta realidade. Também, deve agir para a formação continuada de docentes, para garantir que estejam aptos a trabalhar com os diversos recursos. O novo paradigma mostra que ensinar e aprender exige hoje muito mais flexibilidade espacial e temporal, tanto pessoal, como de grupo, menos conteúdos fixos e processos mais abertos de pesquisa e de comunicação. Assim, não basta a instituição de ensino equipar o seu espaço com os mais modernos recursos tecnológicos se não houver mudança na prática pedagógica.

\section{EXPERIÊNCIAS DE PROJETO DE NOVOS ESPA- ÇOS DE APRENDIZAGEM}

O desenvolvimento de novos espaços de aprendizagem pode ser interpretado como uma resposta a mudança no perfil do estudante, nativo digital, pois cresce na era da televisão e da Internet, com novas expectativas sociais e culturais. Estas necessidades exigem que as instituições de ensino superior mudem os ambientes de aprendizagem, os horários e as exigências (VALEN$\mathrm{TI}, 2015)$. É importante considerar que os alunos e professores estão imersos hoje em informações que circulam nas mídias, especialmente da Internet, que superam de longe os meios acadêmicos (BERNINI et al., 2009). Perrenoud (2000) também aponta o aumento da conectividade dos alunos, produto do rápido desenvolvimento das TIC, exigindo que a instituição de ensino ofereça o apoio midiático para um ensino mais participativo e colaborativo. Os avanços tecnológicos, especialmente dos dispositivos móveis, afetam a educação que infelizmente possui grande inércia e permanência, empregando mais os avanços tecnológicos na gestão escolar e menos no processo de aprendizagem, desmotivando os alunos (MORAN, 2005).

Hoje é importante verificar-se o contraste entre os paradigmas do campus universitário tradicional e as teleuniversidades equipadas com sistemas de aprendizagem interativa e cooperativa, acessíveis de qualquer lugar e tempo. As dimensões e características da infraestrutura e os custos de operação são completamente diferentes, com uma redução drástica (LÉVY, 1999). A mudança na organização dos espaços das escolas é marcada por: novas configurações das salas de aula; otimização da infraestrutura, intensificação do uso dos espaços no tempo; horários flexíveis e menor deslocamento (SQUAIELLA, 2016).

A onda de mudança teve um importante incremento nos últimos anos, especialmente no EUA. A ênfa- 
se tem sido principalmente a transformação das edificações existentes numa atitude de reforma e reciclagem. Os novos recursos tecnológicos e o aprendizado mais centrado no aluno e no trabalho impõem espaços mais flexíveis em tamanho e disposição do mobiliário. $\mathrm{O}$ trabalho atual é baseado em atividades em equipe e de natureza colaborativa, frequentemente de forma virtual e remota, exigindo funcionários mais proativos, criativos e integrados. As instituições universitárias norte-americanas buscam acompanhar estas mudanças laborais (RATHS, 2014).

A aprendizagem ativa é a ênfase baseada na multimodalidade, na flexibilidade, na colaboração, no trabaIho em equipe e em projetos. Os recursos tecnológicos são: Internet de alta velocidade, colaboração em vídeo, visualização de alta resolução e impressora 3-D. O rearranjo físico dos ambientes multifuncionais envolve a capacidade de reorganização rápida e fácil do mobiliário, dos recursos tecnológicos e a preocupação com o conforto acústico e ambiental. Esta preocupação não é tão atual, pois já em 1980 nas primeiras inserções de computadores doados pela Apple na Stanford University's, na Califórnia, a equipe de instaladores sugeriu disposição alinhada dos computadores, que sofreu crítica imediata dos professores que propuseram outras soluções mais adequadas à aprendizagem (RATHS, 2014).

O trabalho em equipe, elemento importante para o novo espaço, foi também desenvolvido na Rensselaer Polytechnic Institute (RPI) em meados da década de 1990, com a combinação de dois alunos por computador. Em 2004 o aprendizado em equipe inspirou a sala de aula no Massachusetts Institute of Technology (MIT), do projeto Technology Enabled Active Learning TEAL, com grupos de até 9 alunos, sendo 3 para cada computador, em sala equipada com telas e projetores de imagem distribuídos em todo o ambiente (VALEN$\mathrm{TI}, 2015)$. Esse conceito também foi aplicado recentemente pela Universidade Metodista, de São Paulo, numa sala de aprendizagem colaborativa e interativa, equipada com tablets, quadros de vidro para fixação de lembretes e protótipos, lousa interativa, mesas redondas para grupos de até quatro alunos e Internet sem fio (METODISTA, 2015).

No segmento de espaços de apoio ao aprendizado destaca-se a Biblioteca para o Século 21 da Santa Clara University, de 2009 projetada por Pfeiffer Patners. Conta com quatro pavimentos, que abrigam áreas de convívio, salas para projetos em equipe, salas de aula e laboratórios especializados (VALENTI, 2015).

Raths (2015) aponta a dificuldade existente ainda hoje para se integrar os diferentes profissionais no sentido de criar um ambiente físico de aprendizagem. Duas outras experiências são muito importantes para elucidar esta questão: a FLEXspace e a Learning Space Rating System.

A FLEXspace foi desenvolvida na The State University of New York com outras universidades norte americanas em 2012, a partir da constatação da falta de referências dos projetistas em conceber as salas de aulas e o ambiente de aprendizagem. A solução é um programa em que as escolas gerenciam e publicam as suas experiências no banco de dados FLEXspace em três áreas básicas: integração de tecnologia, de instalações e aprendizagem/avaliação. A primeira aborda a tecnologia nos espaços, a segunda, o projeto e planejamento do espaço físico e, a terceira, o impacto na aprendizagem. O processo permite o compartilhamento das experiências e conhecimentos voltados à concepção do espaço inovador, valorizando a diversidade de soluções (RATHS, 2014).

O Learning Space Rating System - LSRS (sistema de classificação de espaço de aprendizagem) baseou-se no sistema de classificação de edificações LEED - Leadership in Energy \& Environmental Design, de finalidade ambiental ou construção verde. O LSRS estabelece uma escala de pontuação para o projeto do espaço escolar tendo por objetivo o seu desempenho para a aprendizagem ativa, estabelecendo diferenciais e competição entre instituições, por suas instalações e tecnologia. Atualmente há um processo de sinergia entre os dois projetos em curso, na busca de uma classificação LSRS baseada no banco de dados do Flexspace (RATHS, 2014).

Considerando os grandes avanços tecnológicos, destaca-se uma das experiências mais recentes de sala de aula digital, que é a "Wow Room", na instituição espanhola IE Business School. Equipada com os recursos mais inovadores, ela possibilita a interação simultânea com até 60 alunos, por meio dos sistemas digitais que utilizam a inteligência artificial, as simulações em tempo real, as análises de dados, os robôs interativos, os sistemas de reconhecimento emocional e a presença de especialistas através de hologramas (CAMPOS, 2017).

Os recursos tecnológicos para a simulação virtu- 
al de situações e atividades físicas é muito importante para o ensino e aprendizado remoto em salas de aula e laboratórios virtuais. Na Faculdade Guanambi, há um programa desenvolvido para o curso de farmácia, em 2014, que simula a avaliação clínica em pacientes virtuais, sem riscos (FREEMAN et. al, 2015). A realidade aumentada é a introdução de objetos virtuais em ambiente real, em interações sincrônicas, em três dimensões. Na Universidade Federal de Pelotas é possível decorar um apartamento vazio (real) com mobiliário virtual no curso de arquitetura e urbanismo (TORI; KIRNER; SISCOUTTO, 2006).

\section{CONSIDERAÇÕES FINAIS}

A educação a distância constitui uma oportunidade para a democratização do acesso educacional superior devido ao seu menor custo e a melhor oferta e abrangência espacial e temporal, permitida pela evolução das tecnologias de informação e comunicação.

A escola como um recinto confinado é incompatível com os meios de comunicação modernos, onde é necessária a troca entre as experiências polivalentes. A velocidade das transformações das práticas profissionais e dos conhecimentos teóricos altera o papel do professor, pois as informações são disseminadas por diversos recursos midiáticos e o resultado das pesquisas exige novas reformulações. A própria disposição da sala de aula deverá mudar para incluir a utilização dos recursos eletrônicos, além de propiciar as discussões em grupo e a reflexão e com toda a instituição escolar.

A sociedade está mudando como um todo e também na sua forma de ensinar e aprender. Em um ambiente de crescente interconectividade, a educação é ainda o caminho mais adequado para transformar a sociedade para um futuro mais livre e edificante. No ambiente virtual de aprendizagem, que realiza a interação e comunicação entre professores e alunos, presentes em locais diversos, mas ligados pelo computador, há muitas ferramentas virtuais, de natureza síncrona e assíncrona. Cada ferramenta virtual possui seus atributos, que levam a vantagens e desvantagens, limitando e delimitando o seu emprego. As qualidades textuais são necessárias para que realize sua finalidade no EAD, como tecido estruturado e organizado de significados ditados pela linguagem, segundo regras eruditas, renovadas ao ambiente digital.

A legislação brasileira impõe diretrizes para a oferta do ensino a distância de qualidade, que devem ser incorporadas nas iniciativas para adequação dos espaços de aprendizagem às normas. Apesar da menor utilização destes espaços nesse processo de aprendizagem, se considera como essenciais para o sucesso.

O emprego crescente das tecnologias de informação e comunicação gera ferramentas de aprendizagem potentes que devem conter concepções pedagógicas e espaços de aprendizagem inovadores. O uso destas ferramentas nos AVAs revoluciona o ensino e aprendizagem como forma de criação conjunta do conhecimento, atuando na redução da evasão, possível pela melhor qualidade da comunicação motivadora dos alunos e agentes do EAD.

As sedes e os pólos de apoio devem trazer inovações e não reproduzir os espaços convencionais e tradicionais, produto de concepções industriais ultrapassadas. Para isso, devem possibilitar a flexibilidade no uso dos espaços, além de dar o suporte para as atividades cooperativas e colaborativas. 


\section{REFERÊNCIAS}

BAUMAN, Zygmunt. Modernidade líquida. Rio de Janeiro: Jorge Zahar, 2000.

BERNINI, D. S. D. et al. Nova abordagem nas práticas pedagógicas com o uso das nTICs na Educação Superior. IN: XX Simpósio Brasileiro de Informática na Educação. Florianópolis, SC. 2009.

BRASIL. Congresso Nacional. Lei n. 9394 - Lei de Diretrizes e Bases da Educação Nacional. Brasília: Diário Oficial da União, 23 dez. 1996.

Decreto $n^{\circ} 2.494$ de 10 de Fevereiro de 1998. Regulamenta 0 art. 80 da Lei $n^{\circ}$ 9.394, de 20 de dezembro de 1996, e dá outras providências (referente ensino a distância) - revogado pelo Decreto no 5.622. Diário Oficial da União, Brasília, DF, 11 fev. 1998.

Decreto $n^{\circ} 5.622$, de 19 de dezembro de 2005. Regulamenta 0 art. 80 da Lei no 9.394, de 20 de dezembro de 1996, que estabelece as diretrizes e bases da educação nacional. Diário Oficial da União, Brasília, DF, 20 dez. 2005.

Decreto n $^{\circ} 5.773$ de 09 de maio de 2006. Dispõe sobre o exercício das funções de regulação, supervisão e avaliação de instituições de educação superior e cursos superiores de graduação e sequenciais no sistema federal de ensino. Diário Oficial da União, Brasília/DF, 10 maio 2006.

Ministério da Educação. Portaria N 1.047. Diário Oficial da União. Brasília/DF, 08 nov. 2007a.

Ministério da Educação. Portaria Normativa N. 2. Diário Oficial da União, Brasília/DF, 11 jan. 2007b.

Ministério da Educação. Secretaria de Educação a Distância. Referenciais de qualidade para educação superior a distância. Brasília/DF: SEED/MEC, 2007c.
CAMPOS, Stella. Só nos resta ensinar aos alunos como serem humanos. Valor econômico, 2017. Disponível em: <http://www.valor.com.br/carreira/4924218/so-nos-resta-ensinar-aos-alunos-como-serem-humanos $>$. Acesso em: 07 mar. 2018.

DECCACHE, Renato. A burocracia no caminho do avanço do EAD. Especial Folha Dirigida, Suplemento Educação. Out. 2015.

DORSA, Arlinda Cantero. Linguagem mediada pelas tecnologias de informação e comunicação. Campo Grande: UCDB/Portal Educação, 2016.

FURTADO DOS SANTOS, Júlio Cesar. 0 desafio de promover aprendizagem significativa. Rio de Janeiro: Centro de História e Filosofia do Centro Universitário UNIABEU, 2012.

FREEMAN et. al. NMC technology outllk for brazilian universities: a horizon project regional report. Austin, Texas: The New Media Consortium, 2015.

GADOTTI, M. A educação contra a educação. 4. ed. Rio de Janeiro: Paz e Terra, 1984.

HARVEY, David. Condição pós-moderna: uma pesquisa sobre as origens da mudança cultural. 23. ed. São Paulo: Loyola, 2012.

INEP/MEC, Instituto de Estudos e Pesquisas Educacionais Anísio Teixeira e Ministério da Educação. Censo da Educação Superior 2016. Brasília: Governo Federal, 2017.

LÉVY, Pierre. Cibercultura. São Paulo: Editora 34, 1999.

METODISTA inaugura sala de aprendizagem interativa, com 80 Ipads e Datashow. Universidade Metodista de São Paulo, 24 set. 2015.

MORAN, José Manuel. Aprendizagens inovadoras com tecnologias. Informática na Educação, v. 3, n. 1, set. 2000, p. 141-144. 
As múltiplas formas do aprender. Revista Atividades \& Experiências. Grupo Positivo, p. 11-13. 2005.

PASTORE, José. Defasagem entre tecnologias e a educação. $O$ Estado de São Paulo. 25 de fevereiro de 2014. Disponível em: <http://www.estadao.com.br/noticias/impresso, defasagem-entre-tecnologias-e-a-educacao,1134297,0.htm> Acesso em: 07 mar. 2018.

PERRENOUD, P. Dez novas competências para ensinar. Tradução de Patrícia Chittoni Ramos. Porto Alegre: Artmed, 2000.

RAMOS, Mozart Neves. Brasil tem escola do século XIX, afirma especialista em educação. Globo-News, 08 nov.2012. Disponível em: <http://g1.globo.com/globo-news/noticia/2012/11/brasil-tem-escola-do-seculo-xix-afirma-especialista-em-educacao.html>. Acesso em: 25 mar.2016.

ROPOLI, E. et al. Orientações para o desenvolvimento de cursos mediados por computador. Campinas,SP: EAD Unicamp, 2002.
RATHS, David. How do your learning spaces measure up? Campus Tecnology, Chatsworth/CA, 2014.

SATHLER, Luciano. Audiência pública para o novo marco regulatório do EAD. Brasília: Senado Federal. Comissão de Educação, Cultura e Esportes, 2015.

SQUAIELLA, R. B. F. O desenvolvimento do ensino superior a distância no Brasil - diretrizes para o projeto dos edifícios e redes espaciais. Dissertação (Mestrado em Arquitetura e Urbanismo) na Universidade Presbiteriana Mackenzie, 2016.

SQUAIELLA, R.B.F.; RIGHI, Roberto. Development Prospects for Distance Higher Education in Brazil - New Technologies for the Construction and Dissemination of Education. International Journal for Innovation Education and Research, v. 3, p. 73-83. 2015.

TORI, Romero; KIRNER, Cláudio, SISCOUTTO, Robson Augusto. Fundamentos e tecnologia de realidade virtual e aumentada. In: III SYMPOSIUM ON VIRTUAL REALITY, Belém/PA, 2006.

VALENTI, Mark S. Beyond active learning: transformation of the learning space. Educase Review. Jul./Ago. 2015. p. 30-38. 